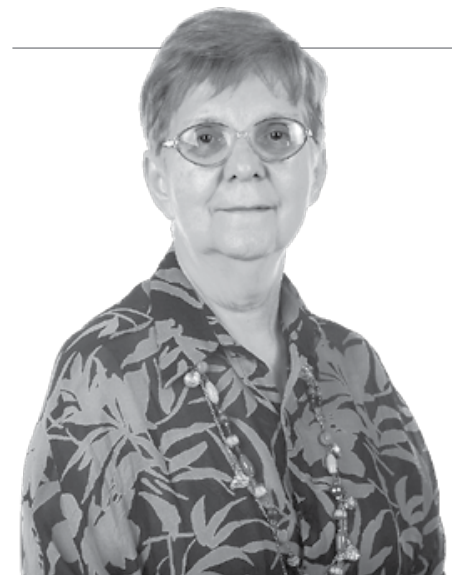

\title{
Repercussões das atividades colaborativas por meio dos recursos tecnológicos no ofício do professor
}

\author{
Effects of through collaborative activities of technological \\ resources in the teacher's craft
}

\section{Efectos de las actividades de colaboración a través de recursos tecnológicos en embarcaciones del maestro}

Na atualidade cada vez mais os professores são convocados a rever suas práticas pedagógicas. As tecnologias trazem uma nova perspectiva que é abordada no presente artigo: as repercussões de atividades colaborativas por meio dos recursos tecnológicos. De que forma e em que medida afetam as praticas pedagógicas dos professores. Trata-se de transpor a escola centrada no ensino para uma centrada na aprendizagem. Nessa Sociedade da Aprendizagem a ênfase é no aprendiz. Aprender a ser aluno é fundamental para aprender a conhecer, a fazer e a conviver.
Nowadays more and more teachers are called upon to review their teaching practices, technologies bring a new perspective that is addressed in this article, the impact of collaborative activities through technological resources. How and to what extent affect the pedagogical practices of teachers. This is to transpose the school focused on teaching to one centered on learning. In this the Learning Society, the emphasis is on the learner. Learning to be a student is critical to learn to know, to do and to live
Hoy en día más y más profesores están llamados a revisar sus prácticas de enseñanza, tecnologías aportan una nueva perspectiva que se aborda en este artículo, el impacto de las actividades de colaboración a través de recursos tecnológicos . ¿Cómo y en qué medida afectan las prácticas pedagógicas de los docentes. Esto es para la transposición de la escuela centrada en la enseñanza a uno centrado en el aprendizaje. En este la sociedad del conocimiento, el énfasis está en el alumno. Aprender a ser un estudiante es fundamental para aprender a conocer, a hacer ya vivir
Palavras-chave: Tecnologia, Atividades Colaborativas, Professor.

\section{Autores:}

\section{Lina Cardoso Nunes}

Doutorado em Educação pela Universidade Federal do Rio de Janeiro em 1990. Atualmente é professora titular da Universidade Estácio de Sá, no Programa de Pós-Graduação em Educação e no Curso de Pedagogia.

E-mail: nunes.lina@yahoo.com.br

\section{Ana Paula Rodrigues Coutinho}

Graduada em Pedagogia pela UERJ/FEBF (1997), graduação em Letras pela Universidade Estácio de Sá (2014), graduação em Gestão de Recursos Humanos pela Universidade Estácio de Sá (2011) e Mestrado em Educação pela Universidade Estácio de Sá (2005). Atualmente é professora titular da Universidade Estácio de Sá e Diretora Adjunta Pedagógica da Fundação de Apoio à Escola Técnica do Estado do Rio de Janeiro FAETEC.

E-mail: aprcoutinho@yahoo.com.br

\section{Introdução}

Vivemos num tempo e num espaço marcados por notáveis avanços tecnológicos acelerados, "consumismo desenfreado", bases científicas e culturais, coexistindo com níveis elevados de pobreza e exclusão social. Este cenário está exigindo das pessoas uma nova forma de colocar-se no mundo.

Nesse contexto, aponta-se o debate sobre o desenvol- vimento das tecnologias de informação e comunicação, que causou um impacto social expressivo e tem estimulado muitas mudanças no mundo (STAHL, 1997). No âmbito desse impacto, a sociedade recebeu a denominação de sociedade da informação, chamada posteriormente de Sociedade da Informação e do Conhecimento e mais recentemente denominada Sociedade da Aprendizagem (ALARCÃO, 2003). No dizer de Alarcão (2003, p.15) não há conhecimento sem aprendizagem: "a escola não detém o monopólio do saber (...) A escola tem que ser uma outra escola (...) tem que ser um sistema aberto, pensante e flexível", constituindo-se um espaço para o aprender.

O contexto descrito impõe desafios à sociedade e também à escola. Segundo Stahl (2001, p.302):

\begin{abstract}
não basta simplesmente transferir o processo ensino-aprendizagem, na forma como ocorre na sala de aula, para uma nova tecnologia, dando ares de modernidade à escola, sem alterações em profundidade. É preciso que os professores estabeleçam o quê, como, onde, por quê, para quê, a quem e para quem servem as novas tecnologias, e só então fazer uso delas, um uso consciente e responsável.
\end{abstract}

Pensamos que a contribuição da tecnologia, por meio do uso de computadores, não pode ser indiferente a nenhum professor, principalmente nos centros urbanos, uma vez que hoje a Pedagogia e a Didática têm recebido inúmeras contribuições dos dispositivos midiáticos. Tardif (apud PERRENOUD, 2000) destaca que se trata de passar de uma escola centrada no ensino para uma centrada na aprendizagem. Na Sociedade da Aprendizagem, coloca-se a ênfase no aprendiz. Aprender 
a ser aluno é fundamental para aprender a conhecer, a fazer e a viver com os outros ${ }^{1}$.

As inovações tecnológicas ${ }^{2}$ que vêm ocorrendo nos levam a modificar as dimensões do pensar, pois transformam o conhecimento que as pessoas têm de si próprias, das outras e de suas relações com o mundo e tem repercussões no âmbito educacional.

Nessa perspectiva, não só os alunos, mas os próprios professores podem desenvolver atividades coletivas por meio da Informática Educativa, contribuindo para o processo de aprendizagem. É a Informática na Educação presente no espaço escolar. De acordo com Valente (2001, p.31) "o termo Informática na Educação tem assumido diversos significados, dependendo da visão educacional e da condição pedagógica que o computador é utilizado".

Na perspectiva dos pesquisadores do Núcleo de Informática aplicada à Educação - $\mathrm{Nied}^{3}$ - a Informática na Educação “significa a integração do computador no processo de aprendizagem dos conteúdos de todos os níveis e modalidades de educação" (VALENTE, 2001, p.31).Hoje 4.640 escolas de Educação Básica da rede pública no Brasil contam com um laboratório e informática, totalizando 53 mil microcomputadores, 326 Núcleos de Tecnologia Educacional - NTEs e 150 mil professores capacitados ${ }^{4}$.

A Informática Educativa não se reduz à utilização de meios, envolve muito mais que colocar computadores nas escolas, e somente se consideradas certas condições, tem potencial para contribuir positivamente para o processo de aprendizagem.

Outro aspecto que precisa ser destacado é a necessidade do apoio indispensável aos professores que estão dispostos a investir tempo e esforço na inovação.Seu envolvimento nas propostas de utilização de informatização pedagógica pode fornecer o impulso e a direção para a mudança (SANDHOLTZ; RINGSTAFF; DWYER, 1997).

Esta mudança remete à reflexão sobre a tecnologia como um conjunto de recursos para a aprendizagem colaborativa, onde alunos e professores tenham mais participação ativa e interativa. De acordo com Behrens (2001, p. 96), a tecnologia pode ser usada como "ferramenta para a aprendizagem colaborativa". Essa estratégia de ensino - aprendizagem, baseada em abordagens teóricas sociais, encara o aluno como agente ativo do processo de aprendizagem.Com vistas a atingir uma determinada meta, pressupõe que os alunos trabalhem juntos em pequenos grupos, considerando que os computadores e a ligação à Internet aumentam o potencial para envolver os alunos em atividades de colaboração. Ressaltamos que uma das competências básicas apontadas no documento Parâmetros Curriculares Nacionais do Ensino Médio é precisamente "Capacidade de pensar múl-

\footnotetext{
${ }^{1}$ A UNESCO instaurou, em 1993, a Comissão Internacional sobre a Educação para o século XXI com o intuito de apontar as tendências da educação para as próximas décadas, gerando o documento conhecido como Relatório Jacques Delors que foi elaborado por especialistas de vários países e indica os quatro pilares da educação nas próximas décadas: aprender a conhecer, aprender a fazer, aprender a conviver e aprender a ser. Nessa perspectiva se enfatiza a formação dos professores para um trabalho educativo eficaz. O quadro que se apresenta requer investimento na Educação Básica destacando-se a formação de professores como um tema crucial e uma das mais importantes políticas para a educação.(BRASIL,1998)

2 A maioria dos estudos sobre inovação sublinha a idéia de "novo", todavia, este entendimento não parte da premissa de que uma inovação implica em algo original.Muitas vezes o "novo" pode estar na introdução de algo que já tem uso corrente noutro lugar.(FARIAS, 2003)

3 Grupo de pesquisa da Unicamp - Universidade de Campinas

${ }^{4}$ Dados disponíveis em www.mec.gov.br/proinfo
}

tiplas alternativas para a solução de um problema, ou seja, do desenvolvimento do pensamento divergente, da capacidade de trabalhar em equipe, da disposição para procurar e aceitar críticas". (BRASIL, 1999, p.24).

Assim, compreendemos que a inserção do computador na escola oportuniza o redesenhar dos papéis de professor e aluno no contexto educacional. O professor - mestre iluminado transmissor de conhecimento - emissor de mensagem fechada, dono da sala de aula baseada no falar-ditar (LEVY, 1993), é convocado agora para ser o mediador de inúmeras informações nas mais diversas vertentes que a informática consegue levar aos alunos. Para o aluno é oferecida a possibilidade de coautoria na construção de conhecimentos.

Diante desse quadro, os professores têm papéis diferentes a desempenhar para o desenvolvimento da aprendizagem de seus alunos. Torna-se necessária uma formação que possa, ao mesmo tempo, prepará-lo para o uso das tecnologias nos processos de ensino, refletir sobre a sua prática e, a partir dela, sobre a construção do conhecimento e de seu compromisso de educador. $\mathrm{O}$ ofício do professor redireciona-se: além do que ensinar trata-se de fazer aprender, utilizando a informática, de usar de competência para utilizar as inovações tecnológicas (PERRENOUD, 2000).

Além dessa competência, Perronoud (2000) refere-se à competência do trabalho em equipe que configura a possibilidade da aprendizagem colaborativa. $\mathrm{O}$ autor afirma que trabalhar em conjunto faz-se uma necessidade. Perrenoud (2000, p.81) define: "Trabalhar em equipe é, portanto, uma questão de competências e pressupõe igualmente a convicção de que a cooperação é um valor profissional."

Nesse sentido, afirma Behrens(2000,p.96):

na Sociedade da Aprendizagem, a tecnologia como ferramenta de aprendizagem colaborativa possibilita os projetos de aprendizagem construídos por professores e alunos. Os professores e alunos podem utilizar a informática para favorecer os processos de interação entre eles.

Essa interação entre professor e aluno contempla na aprendizagem colaborativa a inter-relação e a interdependência dos seres humanos. Citando Behrens (2001, p.78): "A relação é de parceiros solidários (...) que se apropriam da colaboração, da cooperação e da criatividade, para tornar a aprendizagem colaborativa significativa, crítica e transformadora". Alunos e professores envolvem-se com situações de ensino diversas do que estão habituados no processo tradicional.

Pretto (2000, p.46), adverte no Livro Verde 5 :

educar em uma sociedade da informação significa muito mais que treinar as pessoas para o uso de tecnologias da informação e comunicação: trata-se de investir na criação de competências suficientemente amplas que lhes permitam ter uma atuação efetiva na produção de bens e serviços, tomar decisões fundamentadas no conhecimento, operar com fluência os novos meios, ferramentas em seu trabalho, bem como aplicar criativamente as novas mídias, seja em usos simples e rotineiros, seja em aplicações mais sofisticadas. Trata-se também de formar indivíduos para "aprender a aprender", de modo a serem capazes de lidar positivamente com a contínua e acelerada transformação da base tecnológica.

Nessa linha de pensamento, Silva (2001) convoca os professores para que se convertam em formuladores de problemas,

5 "Educação na sociedade da informação", Livro Verde, Brasília (DF), Ministério da Ciência e Tecnologia, 2000 
provocadores de interrogação, coordenadores de equipes de trabalho, sistematizadores de experiências, e memórias vivas de uma educação que, em lugar de aferrar-se ao passado, valorize e possibilite o diálogo entre culturas e gerações. Para isso torna-se necessária uma reformulação drástica na formação desses professores. Um dos pontos dessa reformulação volta-se para a formação para trabalho com as tecnologias, no caso, o uso dos computadores numa dimensão pedagógica.

Conforme Valente (2001) uma das propostas de utilização da Informática na Educação é a de repensar o papel da Escola à luz das novas tecnologias. A relação entre a teoria e a prática, no percurso da formação de professores tem uma dimensão dialética, que leva a uma postura crítica reflexiva diante do processo de ensino e aprendizagem.

Dowbor (apud GADOTTI, 2000), após enaltecer as vantagens da informática, questiona o uso da mesma nas escolas, que hoje não têm nem giz, nem computador sendo que o professor também não dispõe de um salário digno para comprar esse dispositivo tecnológico. O mesmo autor responde que é preciso trabalhar em dois tempos: fazer tudo hoje para superar as condições precárias do atraso das escolas e ao mesmo tempo oportunizar e aproveitar as tecnologias da informação e da comunicação, no ambiente escolar. Ilustrando essa afirmação, a UNESCO realizou uma pesquisa entrevistando 5.000 profissionais do Ensino Fundamental e Médio de escolas públicas e particulares dos 27 estados brasileiros sobre o perfil dos professores brasileiros e os dados demonstram que a maioria dos professores brasileiros não usa o correio eletrônico $(59,6 \%)$, não navega na Internet $(58,4 \%)$, nem se diverte no computador $(53,9 \%)^{6}$ Isto leva a refletir sobre a ausência da Informática na vida cotidiana desse professorado.

Candau (1997) prevê que somente a capacidade do professor para selecionar e explorar as tecnologias adequadas ao seu contexto dará a devida dimensão do seu uso na educação, ressaltando que esse uso só terá uma repercussão caso conte com o apoio dos professores Daí a importância da atitude do professor como fator significativo no uso do computador, propiciando a aprendizagem colaborativa.

Assim, a práxis ${ }^{7}$ do professor familiarizado, com as tecnologias da informação e comunicação deve ser um processo que, segundo o Programa Nacional de Informática na Educação -ProInfo ${ }^{8}$ - (BRASIL, 2000), o mobilize e prepare para incitar seus alunos a "aprender a aprender", tendo autonomia para selecionar as informações pertinentes à sua ação, compreender os conceitos envolvidos, analisando as situações - problema e escolhendo a alternativa adequada de atuação para resolvê-las, assim como, refletindo sobre os resultados obtidos, depurando seus procedimentos e reformulando, se preciso, as suas ações, numa dimensão colaborativa. Criar esse ambiente favorece a construção de uma sociedade solidária, porque essa dimensão colaborativa valoriza a aprendizagem em grupo, envolve além dos alunos, os professores e os gestores da educação, uma vez que:

depreende-se que uma postura cooperativa exige colaboração dos

\footnotetext{
${ }^{6}$ A pesquisa completa pode ser encontrada no site www.unesco.org.br

${ }^{7}$ Práxis - Na Filosofia Marxista, a palavra grega práxis é usada para designar uma relação dialética entre o homem e a natureza. A filosofia da práxis se caracteriza por considerar como problemas centrais para o homem os problemas práticos de sua existência concreta (JAPIASSU; MARCONDES, 1996, p.49).

8 PROINFO - Programa Nacional de Informática na Educação instituído em 1997 atende 4.640 escolas ,possui 53 mil computadores,326 Núcleos de tecnologia Educacional e conta com 150 mil professores capacitados (BRASIL, 2000)
}

sujeitos envolvidos no projeto, tomada de decisões em grupo, troca e conflitos sociocognitivos, consciência social, reflexão individual e coletiva, tolerância e convivência com as diferenças, responsabilidade do aprendiz pelo seu aprendizado e pelo grupo, constantes negociações e ações conjuntas e coordenadas. (BEHRENS, 2001, p.106)

Nessa dimensão o professor deve planejar atividades que ajudem os estudantes a descobrir e tirar vantagem da heterogeneidade do grupo para aumentar o potencial de aprendizagem de cada um dos membros do grupo. Sendo o espaço de formação profissional ideal para a implementação dessa metodologia de ensino-aprendizagem, especialmente, no âmbito de projetos de aprendizagem colaborativa.

O presente artigo tem como foco central a problemática que vem desafiando aos professores do Curso Normal, instigando as possibilidades para desenvolver processos que focalizem a aprendizagem colaborativa por meio do uso de computadores. Considera-se, nesse sentido que a absorção das novas metodologias, para ensinar e para aprender, precisa levar em consideração o mundo tecnológico que se implantou nas últimas décadas do século XX.

Nesse âmbito se insere o presente artigo que aborda os Cursos de Ensino Médio - na modalidade Normal e as possibilidades de criação de um ambiente de aprendizagem colaborativa por meio da Informática Educativa.

A Informática aplicada à Educação vai progressivamente abrindo espaços na sociedade contemporânea. Perrenoud (2000) coloca que a verdadeira incógnita é saber se os professores irão se apossar das tecnologias, especialmente, do computador, como um auxílio ao ensino, para dar aulas melhor ilustradas, ou para mudar de paradigma e concentrar-se na criação, na gestão e na regulação de aprendizagem.

Assim, com a crescente tendência de pensar a educação na Sociedade da Aprendizagem questiona-se o espaço para a formação de professores em uma sociedade que se propõe à inclusão social como uma das prioridades. A formação dos professores pouco tem se alterado nas últimas décadas, ignorando os avanços tecnológicos, apesar de algumas escolas contarem com laboratórios de informática e capacitações para os docentes.

De acordo com Stahl (1997, p.312):

as tentativas para incluir o estudo das novas tecnologias nos currículos dos cursos de formação de professores esbarram, quase sempre, nas dificuldades com o investimento exigido para a aquisição de equipamentos, e na falta de professores capazes de superar preconceitos e práticas cristalizadas que rejeitam a tecnologia, e mantém um tipo de formação em que predomina a reprodução de modelos que já deviam ter sido substituídos por outros mais adequados à problemática educacional.

Nesse sentido as disciplinas do curso Normal, formação inicial de professores, poderiam articular seus conceitos com a Informática Educativa, construindo um ambiente de aprendizagem colaborativa. A criação de ambientes de aprendizagem colaborativa apoiada por computador é uma das alternativas atuais do novo enfoque da aprendizagem, fundamentada em teorias sócio-interacionistas (Vygotsky, 1984)

Assim, o presente artigo direciona-se à ampliação do conhecimento acerca do uso da Informática aplicada à Educação na modalidade de Ensino Médio Normal, bem como as repercussões das atividades colaborativas por meio dos recursos tecnológicos no ofício de professor. 


\section{O percurso da investigação}

A pesquisa em foco realizou-se no Instituto de Educação Professor Móyses Henrique dos Santos, em São João de Meriti, sendo focalizados os aspectos qualitativos acerca das contribuições e implicações do uso da Informática Educativa no Curso Normal. A escolha para estudo se justifica por ser uma escola de referência no Município, com 1.300 (um mil e trezentos alunos), abrigando 87 professores com experiência de atuação no Curso de Formação de Professores, alguns com Mestrado e vários especialistas. É importante para o presente estudo acrescentar que o Instituto de Educação Professor Moysés Henrique dos Santos participa do ProInfo - Programa de Informatização das Escolas Públicas.

O Instituto de Educação Professor Móyses Henrique dos santos, foi escolhido por ser uma referência no município, com 1.251 (um mil e duzentos e cinquenta e um alunos), abrigando 87 docentes com grande experiência de atuação no Curso de Formação de Professores, alguns com Mestrado e vários especialistas, participando, ainda, do ProInfo - Programa de Informatização das Escolas Públicas.

A estrutura curricular do Curso Normal do referido Instituto de Educação segue as diretrizes estabelecidas pela Resolução SEE n 2353, de 28 de dezembro de 2000 e pela portaria E/Suen $n^{\circ} 07$, de 22 de fevereiro de 2001. Ainda, os componentes curriculares de Base Nacional Comum, atendem aos princípios das Diretrizes Curriculares Nacionais para o Ensino Médio(DCNEM).

A escola participa do projeto ProInfo, pertencendo a abrangência do Núcleo de Tecnologia Educacional de Nilópolis ( RJ 12) . O ProInfo é um programa educacional criado em 9 de abril de 1997 pelo MEC - Ministério da Educação (Portaria MEC 522) para implementar o uso da Telemática como ferramenta de potencialização pedagógica no ensino público fundamental e médio, cujas estratégias de avaliação constam do documento Diretrizes do Programa Nacional de Informática na Educação, de julho de 1997.

Participaram da presente pesquisa: a equipe técnica pedagógica formada por três Coordenadoras Pedagógicas, três Orientadoras Educacionais e três diretores, sendo uma diretora geral e os oitenta e sete professores que atuam no Instituto de Educação do Curso Normal em Nível Médio.

A observação do campo de pesquisa privilegiou a pesquisa qualitativa, não se resumiu em olhar, mas foi estruturada, a partir de um roteiro, com registro temporal e com anotações em caderno de campo; compreendeu descrições, explicações e registro de observações e reflexões que realizamos sobre expressões ou ações dos pesquisados (TRIVIÑOS, 1997).De acordo com Lüdke e André (1986, p.26) a observação direta "permite também que o observador chegue mais perto da" perspectiva dos sujeitos", um importante alvo nas abordagens qualitativas". Foi também utilizado o questionário que segundo Rizzini (1999 p. 77):

consiste em uma série de perguntas e questões, cuja forma, aberta ou fechada, configura tipos de coleta de dados qualitativos e quantitativos, respectivamente. O questionário pode ser dirigido ao entrevistado pelo entrevistador, de forma direta, ou preenchido pelo próprio entrevistado.

Outro instrumento utilizado foi a entrevista semiestruturada que segundo Rizzini (1999, p. 63): "é aplicada a partir de um pequeno número de perguntas, para facilitar a sistematização e codificação. Apenas algumas questões e tópicos são pré-determinados".

Para aprofundar aspectos relativos aos questionamentos foi realizado o grupo focal, é uma técnica não - diretiva, cujo resultado no caso dessa pesquisa visou o controle da discussão de um grupo de alunos. Levantaram-se opiniões e considerações sobre o tema nos encontros com os grupos de alunos. $\mathrm{O}$ facilitador da discussão deve estabelecer a discussão e não realizar uma entrevista com o grupo. É utilizado na coleta de novas informações, permitindo ainda coletar dados qualitativos para avaliação dos resultados, através da realização de entrevistas informais e conversas abertas. Foram organizados grupos pequenos com cerca de 8 alunos.

Os achados relativos às entrevistas semiestruturadas e aos grupos focais foram analisados de acordo com a técnica de análise de conteúdo, na modalidade análise temática(BARDIN,1997)

\section{Apresentando os resultado:}

Com base nas entrevistas semiestruturadas com os professores e as respostas do grupo focal realizado com os alunos, surgiram quatro temas, que serão descritos brevemente a seguir.

O primeiro tema relativo aos Projetos Pedagógicos desenvolvidos no laboratório de Informática. Nele ficaram evidenciados como os participantes envolvidos na pesquisa percebem a importância do professor ter um projeto pedagógico que utilize a informática para agregar conhecimentos aos alunos em suas disciplinas.

Percebe-se em grande parte das falas dos participantes o destaque aos trabalhos desenvolvidos no laboratório pelos professores, evidenciando que as aulas com a informática são desafiadoras e não aulas mecânicas.

Observa-se que os professores que usam a sala de Informática procuram a Internet como fonte de conhecimento para complementar o conteúdo abordado em sala de aula, articulados aos projetos pedagógicos, conforme pode ser constatado nos comentários, a seguir pelos alunos sobre as atividades vivenciadas e os conteúdos referentes aos projetos discutidos.:

PI 4 - Minha turma trabalhou com a questão do Conselho Nacional de Educação e os órgãos. Fizemos pesquisas, acessamos o site do CNE, vimos as atribuições, algumas deliberações do Conselho, os participantes do Conselho

PI 1 - Utilizei com a Informática Básica, criação de Home Page e pesquisa de conteúdo para Didática. Tive o auxilio de um monitor - um rapaz formado em Informática que fazia como voluntário um trabalho no laboratório. As aulas práticas ocorriam no Laboratório. Em três momentos: iniciar, aprofundar e pesquisar. Iniciei no Paint; Ensinei a criar e-mail,gravar os desenhos, enviar os desenhos por e-mail,Tabela no excel, Texto e desenho, construção de texto coletivo, na tentativa de interdisciplinar.

PI 3 - entramos também nos sites das Secretarias dos estados do Rio de janeiro, do Ceará e da Bahia, fazendo uma pesquisa mesmo de atuação dessas secretarias como é trabalhado o Ensino de Jovens e Adultos, merenda escolar e os projetos desenvolvidos por essas secretarias. O laboratório foi utilizado para pesquisa, a confecção do relatório sobre o que eles pesquisaram no Word e também eles entraram no site da SEE, ouvidoria, fale com a SEE e eles colocaram sobre a questão do passe livre.

O segundo tema Contribuições da Informática reflete a conscientização dos participantes da pesquisa em relação ao mundo em que vivemos e a necessidade da modernização. A grande maioria dos alunos enaltece a importância da Informática na elaboração dos trabalhos escolares, bem como a influência dela para o seu futuro profissional e contribuição da mesma na apropriação de conhecimentos e informações.

A7 - A informática é um recurso fundamental em termos de 
pesquisa e inclusão profissional.

A 1 - Além de ajudar a professora, a gente também trabalha com as crianças e nós mesmos usamos a Internet, pesquisando sites,fazendo pesquisas...

A4 - A informática, hoje em dia é básico, como Inglês e Espanhol, nas nossas vidas.

O terceiro tema está associado às Dificuldades com a Informática, que aparecem nos depoimentos dos participantes, abordando os entraves apresentados por alunos e professores para a utilização do laboratório de Informática. A resistência dos professores, a falta de tempo apontada pelos professores para elaboração de atividades que possam contemplar a sala de informática, o despreparo do professor para a utilização das inovações tecnológicas e por fim o número excessivo de alunos por turma,cujos laboratórios de informática não comportam.

PI 2 - De inicio precisamos quebrar o gelo, tinha gente que odiava computado, entre eles havia uma relação somente de ódio (...)

PI4 - Eles são muito participativos. Só lamento que o laboratório é pequeno e dificulta o nosso trabalho a gente tem um desgaste maior Vamos torcer para que cada sala tenha o seu computador, porque a gente também já prepara nossa aula em Pt e apresenta.

P28 - Não houve curso preparatório para sua utilização, não nutro simpatia pelo uso desse recurso; não acredito que o recurso amplie as condições de aprendizagem;o livro continua sendo o melhor instrumento para a pesquisa pedagógica

\section{$\mathrm{O}$ aluno participante $\mathrm{A} 3$ também reflete em suas coloca-}

ções sobre as dificuldades encontradas:

A3 - Uma dificuldade que nós tivemos foi que muitas crianças estão na $2^{\mathrm{a}}$ e $3^{\mathrm{a}}$ séries e não sabem ler e isso dificultou o nosso trabalho, porque para interagir melhor com o computador é preciso leitura e eles não conseguiam. $\mathrm{O}$ que não impediu que elas aprendessem.

O tema seguinte aponta para os indicadores de Aprendizagem Colaborativa, foco deste trabalho, levantando os aspectos relacionados ao diálogo e à reflexão, à participação e à colaboração entre alunos com os alunos e dos professores com os alunos e o uso do computador como interface

A aprendizagem colaborativa depende da abordagem pedagógica que a valorize, por meio de professores que redimensionem a sua prática, objetivando ultrapassar os muros escolares. Uma proposta pedagógica que oportunize ao discente a produção do conhecimento e que o estimule a ser autônomo, inovador e com capacidade de reconhecer e refletir obre a sua realidade.(BEHRENS, 2000).Podemos analisar esse indicadores nas falas a seguir:

PI 1 - No laboratório de Informática é que nós professores nos despimos. do falso saber, eu sei tudo, eu sou a autoridade máxima, lá dentro você ensina e aprende, o aluno te ensina e a gente se transforma em colegas de turma .Uma troca muito grande. Uma coisa maravilhosa. Aprendi muito no laboratório. Eu queria ter mais tempo, daria minhas aulas no Laboratório Acho que eles cresceram e eu também cresci

PI 1 - No laboratório de Informática é que nós professores nos despimos daquela...do falso saber, eu sei tudo, eu sou a autoridade máxima, lá dentro você ensina e aprende, o aluno te ensina e a gente se transforma em colegas de turma .Uma troca muito grande. Uma coisa maravilhosa. Aprendi muito no laboratório. Eu queria ter mais tempo, daria minhas aulas no Laboratório Acho que eles cresceram e eu também cresci

A4 - Fizemos esse trabalho com os próprios amigos da sala de aula. Aquelas pessoas que não sabiam nem como ligar um computador vinha para cá (sala de informática) depois das aulas ensinar e aprender informática.

A6 - A própria professora de Prática havia dito que havia coisas que ela não sabia e aprendeu com a gente. Isso é legal! Tanto a gente aprende com ela como ela aprende com a gente.

\section{Considerações Finais}

Os desafios e as perspectivas que se apresentam na aprendizagem colaborativa no Ensino Médio - Modalidade Normal - são apontados pelos participantes da presente pesquisa. As práticas pedagógicas observadas no decorrer da pesquisa revelam que a informática ainda não faz parte do mundo dos professores formadores de professores No presente estudo de caso.Embora os resultados do estudo não sejam generalizáveis é preocupante em se tratando de uma escola de formação de professores.

Apesar disso, as falas dos participantes da pesquisa apontaram para a importância da inserção das tecnologias da informação, do computador e do laboratório, no cotidiano pedagógico. Mesmo assim, foi sinalizado que poucos professores levam seus alunos a sala de informática e criam estratégias para utilizá-la, uma vez que o número de máquinas é inversamente proporcional ao número de alunos. Entretanto os alunos são unânimes em reconhecer as contribuições da informática, seja em âmbito pessoal ou profissional, bem como na apropriação de conhecimentos.

Considera-se, a princípio, que não é possível pensar num curso de formação de professores que não contemple a informática educativa. A educação precisa encarar a informática de uma forma ampla que ultrapasse os muros da escola, formando seus alunos para o ambiente digital. Segundo Branco (2003, p.417) "O humano e o tecnológico não podem ser vistos como forças antagônicas dentro da sociedade como um todo e da educação em particular". Nesse contexto, a educação perde seu monopólio do saber, desencontra-se da sua forma habitual de ensinar e confronta-se com um novo aluno, que emerge de uma geração tecnológica.

Após considerarmos sobre os objetivos desse trabalho, os desafios e as perspectivas apontadas refletem que não basta que existam políticas públicas que incentivem o uso dos computadores no Ensino Médio - Modalidade Normal, para que esse fato se efetive, não é por usar trabalhos em grupo que se está utilizando a aprendizagem colaborativa e que é necessário que o professor esteja pré - disposto a abraçar essa causa, porque a utilização da tecnologia depende da forma como o professor vai utilizá-la em seu cotidiano.

Fica então a nossa provocação, façamos o uso da Informática Educativa, em Laboratórios das escolas formadoras de professores numa perspectiva colaborativa de aprendizagem, não com o objetivo de elevá-la ao patamar de salvadora da crise educacional, mas de uma maneira reflexiva de que sociedade queremos, uma vez que a tecnologia não é independente da sociedade, uma vez que não há neutralidade, nem na ciência,nem na escola.

Nesse sentido julgamos que as questões sobre o uso da Informática Educativa nas Escolas de Curso Normal, de forma colaborativa devem sair do âmbito professor/ aluno e ampliar a discussão nas comunidades escolares, na tentativa de repensar uma nova educação que possibilite a inclusão digital de forma progressiva dos professores que já atuam e dos que estão se preparando para atuar. 


\section{REFERÊNCIAS}

ALARCÃO, I. Professores reflexivos em uma escola reflexiva. São Paulo: Cortez, 2003.

ALVES, N. G. Formação de professores possibilidades do imprevisível. Rio de Janeiro: DP\&A, 2004.

ALVES, N. Formação de Professores: Pensar e Fazer. $4^{\mathrm{a}}$ ed. São Paulo: Cortez, 1996.

ANDRÉ, Menga. A pesquisa sobre formação de professores no Brasil-1990-1998.In CANDAU, Vera Maria (org.) Ensinar e aprender: sujeitos saberes e pesquisa. Encontro Nacional de Didática e Pratica de Ensino- ENDIPE - RJ: DP\&A, 2001.

BEHRENS, M A .Projetos de aprendizagem colaborativa num paradigma emergente. In: MORAN,J.M. t al. Novas Tecnologias e mediação Pedagógica. Campinas, S.P.: Papirus,2001.

BRANCO, A C . A portaria $n^{\circ} 2.253 / 2001$ no contexto da evolução da educação a distancia nas instituições de ensino superior no Brasil. in SILVA. M. Educação online São Paulo: Loyola,2003

BRASIL CONSELHO FEDERAL DE EDUCAÇÃO.Lei de Diretrizes e Bases da Educação Nacional, 9394 / 96 de 20 de dezembro de 1996.

BRASIL, MINISTERIO DA EDUCAÇÃO. Referenciais Nacionais da Formação de Professores Brasília: MEC,1999

BRASIL, ProInfo - informática e formação de professores.Brasília: Ministério da Educação, Seed, 2000.

BRASIL, Secretaria de Educação à Distância. Programa de Informática na Educação. Documento produzido pela Secretaria de Educação à Distância do Ministério da Educação e do Desporto (MEC/SEED). III reunião extraordinária do CONSED. 19-20 de setembro de 1996. Disponível em: <http://www.mat.unb.br/ead/MEC> Acesso em: 29 abr. 2001.

CANDAU, Vera Maria (org.) Ensinar e aprender: sujeitos saberes e pesquisa. Encontro Nacional de Didática e Pratica de Ensino- ENDIPE - RJ: DP\&A, 2001.

ENGUITA, M. F. O magistério numa sociedade em mudança.In VEIGA, Ilma Passos A (Org.). Caminhos da profissionalização do magistério.São Paulo: Papirus, 1998.

GADOTTI, M. Perspectivas Atuais da Educação.Porto: Alegre: Artes Médicas Sul, 2000.

JAPIASSÚ, H; MARCONDES, D. Dicionário Básico de Filosofia. $3^{\text {a }}$ ed. Ver. E ampliada- R.J. : Jorge Zahar ED., 1996

LÉVY, P. As Tecnologias da inteligência: o futuro do pensamento na era da informática. Rio de Janeiro: Editora 34, 1993.

LUDKE, M. ; ANDRÉ, M. E. D. A . Pesquisa em educação: abordagens qualitativas.São Paulo; EPU,1986

MORAN,J.M. t al. Novas Tecnologias e mediação Pedagógica. Campinas, S.P.: Papirus, 2001.

NUNES, C. Ensino Normal - Formação de professores .Rio de janeiro: DP\&A,2002.

PERRENOUD, Philippe. Dez novas competências para ensinar, tradução Patrícia Chittoni Ramos .Porto Alegre : Artmed, 2000

PRETTO, N (coord.). Educação na sociedade da informação, Livro Verde, Brasília (DF), Ministério da Ciência e Tecnologia, 2000, p. 43-56.

RIZZINI,I at alli. Pesquisando... Guia de metodologias de pesquisa para programas sociais. Rio de Janeiro: Editora Universitária Santa Úrsula, 1999

SANDHOLTZ, J. H.; RINGSTAFF, C.; DWYER, D. Ensinando com Tecnologia. Trad.Marcos Antonio Guirado Domingues- Porto Alegre:Artes Médicas, 1997.

SILVA, M. Sala de aula interativa. $2^{\mathrm{a}}$ edição, Rio de Janeiro: Quart, 2001. Educação online São Paulo :Loyola,2003.

STAHL, M. M. Formação de professores para uso das novas tecnologias de comunicação e informação. In CANDAU, V. M. (org.)
Magistério: Construção Cotidiana RJ : Vozes, 1997

TRIVIÑOS, A . N. Introdução à pesquisa em ciências sociais: a pesquisa qualitativa em educação. São Paulo:Atlas, 1887.

VALENTE,J.A . O computador na sociedade do conhecimento. Campinas, São Paulo :UNICAMP/NIED,2001

VEIGA, I. P. A(Org.). Caminhos da profissionalização do magistério. São Paulo: Papirus, 1998.

VYGOTSKY, Lev S. A formação social da mente. S. P. : Cortez,1984. 